Didáctica Geográfica n 21, 2020,pp. 97-123

DOI: https://doi.org/10.21138/DG.545

ISSN electrónico: 2174-6451

\title{
WALKING TOUR COMO ESTRATEGIA DE APRENDIZAJE EN GEOGRAFÍA APLICADA A SARGADELOS (LUGO)
}

\author{
WALKING TOUR AS GEOGRAPHY LEARNING STRATEGY APPLIED IN \\ Sargadelos (Lugo)
}

WALKING TOUR COMME STRATÉGIE D'APPRENTISSAGE EN GÉOGRAPHIE APPliquée à SARgadelos (Lugo)

Keumbee Lee

Universidad Autónoma de Madrid

goodlkb@gmail.com

Alfonso García de la Vega

Universidad Autónoma de Madrid

alfonso.delavega@uam.es

Recibido: 31/05/2020

Aceptado 09/09/2020

\section{RESUMEN:}

Este trabajo analiza la relación entre la industria de la cerámica y su localización geográfica, su influencia en el paisaje y sus valores educativos, destacando el valor de paisaje. Poniendo el foco en el papel de los museos como institución educativa, se examina el potencial de estos lugares para realizar actividades que puedan proporcionar los valores geográficos utilizando la estrategia de aprendizaje de walking tour. Por último, se propone una experiencia educativa para el Museo Histórico de Sargadelos 
relacionada con el currículo de Educación Secundaria Obligatoria y Bachillerato. Se espera que esta actividad pueda ofrecer una experiencia complementaria en comparación con la tradicional educación museística, en la que la aproximación geográfica ha sido habitualmente soslayada en favor de contenidos históricos o artísticos.

\section{Palabras Claves:}

Estrategia de aprendizaje; walking tour; paisaje industrial; cerámica; Sargadelos.

\section{Abstract:}

This article analyzes the relationship between the ceramic industry and its geographical location, its influence on the landscape, and its educational values, highlighting the landscape's value. This paper focuses on the museum's rol as an educational institution. It examines the potential of these museums to carry out activities that can provide geographic values using the walking tour as a learning strategy. Lastly, an educational suggestion is proposed for the Historical Museum of Sargadelos related to the Secondary Education and Baccalaureate curriculum. This activity can offer a complimentary experience than the traditional museum education, in which the geographical approach has been frequently overlooked in favor of historical or artistic content.

\section{KEYWORDS:}

Learning strategy; walking tour; industrial landscape; ceramics; Sargadelos.

\section{RÉSUMÉ:}

Ce travail analyse la relation entre l'industrie de la céramique et sa localisation géographique, son influence sur le paysage et ses valeurs éducatives, en soulignant la valeur paysagère. En se concentrant sur le rôle des musées en tant qu'institution éducative, il examine le potentiel de ces lieux pour mener des activités qui peuvent fournir des valeurs géographiques en utilisant la stratégie du walking tour. Enfin, il y est proposé une expérience éducative pour le Musée historique de Sargadelos concernant le programme d'enseignement secondaire et le baccalauréat. On espère que cette activité pourra offrir une expérience complémentaire par rapport à l'éducation muséale traditionnelle, où l'approche géographique a été habituellement négligée en faveur de contenus historiques.

\section{Mots-CLÉs:}

Stratégie d'apprentissage; walking tour; paysage industriel; céramique; Sargadelos. 


\section{INTRODUCCIÓN}

La cerámica es una de las más antiguas manufacturas humanas y tanto a través de su uso doméstico como del decorativo-ceremonial cumple al mismo tiempo una función práctica y artística. Numerosos investigadores han centrado sus estudios en aspectos relacionados con su producción (Jacquemart, 1873; Arnold, 1985; Medley, 1980; Kang, 2012). Sin embargo, en los últimos años, la tendencia de las investigaciones se dirige hacia el análisis de los intercambios entre diferentes culturas. A medida que la producción de cerámica sufrió el proceso de industrialización, las fábricas cambiaron el paisaje, pues intervinieron en el territorio. De este modo, el paisaje natural y el paisaje artificial se modifican debido a las instalaciones y los subproductos asociados a la producción.

Hasta ahora, la relación entre la fabricación de cerámica y su entorno y el paisaje desde un punto de vista educativo ha sido poco explorada. No obstante, en este trabajo se examinarán las condiciones geográficas y ventajas educativas que presentan los lugares de producción de cerámica. Además, la fabricación de cerámica constituye una de las industrias principales de la región y es un factor que influye en su paisaje. Por ello, se analizará el papel educativo del museo de cerámica/ histórico de este lugar y los métodos educativos recomendados. Para finalizar, se presentan las características de la localización de la fábrica de cerámica de Sargadelos en Cervo (Lugo) y se propone una actividad museística utilizando los valores geográficos de la zona con respecto al currículo de Educación Secundaria Obligatoria y Bachillerato.

\section{LA PRODUCCIÓN DE CERÁMICA Y EL PAISAJE INDUSTRIAL}

La localización de los lugares de producción de cerámica y su relación con las fuentes de materias primas han sido ampliamente estudiadas desde un punto de vista arqueológico. Las investigaciones recientes, sin embargo, han abordado su estudio desde un punto de vista más amplio, considerando su importancia cultural y el potencial como elemento de estudio para el análisis de la Geografía humana del territorio (Symonds, 1999). El estudio de la cerámica también muestra interacciones entre la sociedad y el paisaje (Michelaki et $a l, 2015)$ o de qué modo su producción afectó al desarrollo económico de una determinada región en un momento concreto (Vrkljan y Konestra, 2018).

\subsection{La localización de la fabricación de cerámica}

A partir de la industrialización, la relación entre la localización de las fábricas y los factores geográficos del lugar han sido objeto de investigación para estudios centrados en la Geografía económica (Rangiya, 2007). Así, estos lugares de producción fueron instalados dependiendo de la cercanía y la facilidad para encontrar y transportar las materias primas: los bosques, para conseguir combustible, y las fuentes de agua y 
los minerales, como el caolín. Por ejemplo, Jingdezhen, el lugar más importante en la producción de cerámica en China, se encuentra en la zona donde las condiciones naturales únicas proporcionan abundantes materias primas, combustible, luz solar, energía y recursos hidráulicos para la producción (Zhan, 2012).

Hay que tener en cuenta que se trata de industrias que demandan gran cantidad de recursos naturales que fueron extraídos de sus inmediaciones. Por ello se excavaron minas, se usaron rutas fluviales para el transporte y se desarrollaron otras industrias auxiliares que dieron soporte a la producción de cerámica. Alfrey y Clark (2005) señalaron cómo en el caso de Gorge (Inglaterra), dado al bajo valor asociado a los ladrillos y azulejos en comparación con la producción de otros productos cerámicos, sus fábricas se instalaron cerca de las canteras de arcilla porque es una materia prima voluminosa y de este modo se minimizaban los costes de su transporte.

\subsection{La modificación del paisaje por la producción de cerámica}

Gran parte de nuestro territorio está ocupado por instalaciones industriales y sus construcciones subsidiarias de minería, producción y transporte (Trachana, 2011), por lo tanto, es necesario llamar la atención sobre los paisajes modificados por estos centros de fabricación. Así, la relación entre la producción de cerámica y su entorno también ha determinado unos paisajes locales marcados por sus rasgos industriales y una manufactura que ha intervenido decisivamente en la configuración de los paisajes.

Dentro del marco internacional, en la Convención del Patrimonio Mundial del 1992 se estableció la siguiente definición de paisaje cultural: "Cultural landscapes represent the combined works of nature and of man' designated in Article 1 of the Convention" (UNESCO, 1994, p. 13). En este contexto, las infraestructuras industriales que forman parte del patrimonio cultural de la UNESCO son consideradas como un paisaje cultural a nivel mundial, pero Rodrigues da Silva (2012) señala que es necesario analizar la relación entre el patrimonio cultural industrial y el paisaje cultural desde una perspectiva regional.

A nivel europeo, el Convenio Europeo del Paisaje (Unión Europea, 2000, p. 11) define un paisaje de una forma más genérica: "se entenderá cualquier parte del territorio tal como lo percibe la población, cuyo carácter sea el resultado de la acción y de la interacción de factores naturales y/o humanos". Sodano (2017) apunta que la perspectiva de este convenio destaca los aspectos del paisaje de la vida cotidiana y un paisaje degradado, que no estaban presentes en la Convención de la UNESCO. Además, considerado desde un nivel nacional, el pasiaje configurado por las actividades industriales está listado en las categorias de paisajes culturales del Plan Nacional de Paisaje Cultural de España. (Ministerio de Educación, Cultura y Deportes, 2015a). 
En España, el catálogo de paisajes culturales registra numerosos casos de marcado carácter industrial. En este contexto, Sodano proporciona una definición esquematizada de paisaje cultural: "Los paisajes culturales son aquellos en los que la interacción humana con el entorno natural, durante un largo período de tiempo, ha dado lugar a un paisaje característico" (Sodano, 2017, p. 83). Hay paisajes cuyos rasgos dominantes se vinculan a la actividad minera, hidráulica y ferroviaria. Los paisajes muestran un marco histórico, donde se produjeron las mayores modificaciones en el territorio. La explotación aurífera de época romana de Las Médulas (León) y la explotación medieval de las salinas de Añana (Álava) impregnan al paisaje unos rasgos culturales (Ministerio de Educación, Cultura y Deportes, 2015b). En ambos casos, el dominio cultural subyuga el territorio, resultando difícil establecer el umbral entre naturaleza e intervención humana (García de la Vega, 2014).

Por tanto, Trachana ha abordado su idenfiticación basándose en la definición proporcionada por Franco Borsi - "la forma que el hombre imprime consciente y sistemáticamente al paisaje natural o agrícola, en el curso y con el fin de desarrollar sus actividades industriales (Borsi, 1975)" (cit. por Trachana, 2011, p. 194). Trachana (2011) considera que el paisaje cultural se impregna de la memoria e historia de la sociedad industrial. Este es el valor, como afirma el mismo autor, que ha de preservarse como legado cultural.

Con respecto a la producción de cerámica, se puede observar el paisaje modificado por la explotación de minas para conseguir diferentes tipos de arcilla, como son el caolín, gres, arcilla roja y bentonita (Figura 1). Estas modificaciones son más pronunciadas a medida que avanza la industrialización. Homobono (1987) mencionó que en el Valle de Regato las operaciones mineras de la industria cerámica tradicional antes de la industrialización han dejado escasa influencia en el paisaje. Khor (2005) también señaló que la producción industrializada de la cerámica ejerce un gran impacto en el paisaje y, a veces, crea paisajes abandonados.

Además, la industria también interviene el paisaje de un modo diferente: la instalación de las fábricas. Estas modifican el paisaje dándole un nuevo carácter, y son estos paisajes los que generalmente se denominan industriales, caracterizándose principalmente por edificios uniformes de ladrillos, chimeneas imponentes y otras edificaciones, como molinos de agua (Figura 2). 


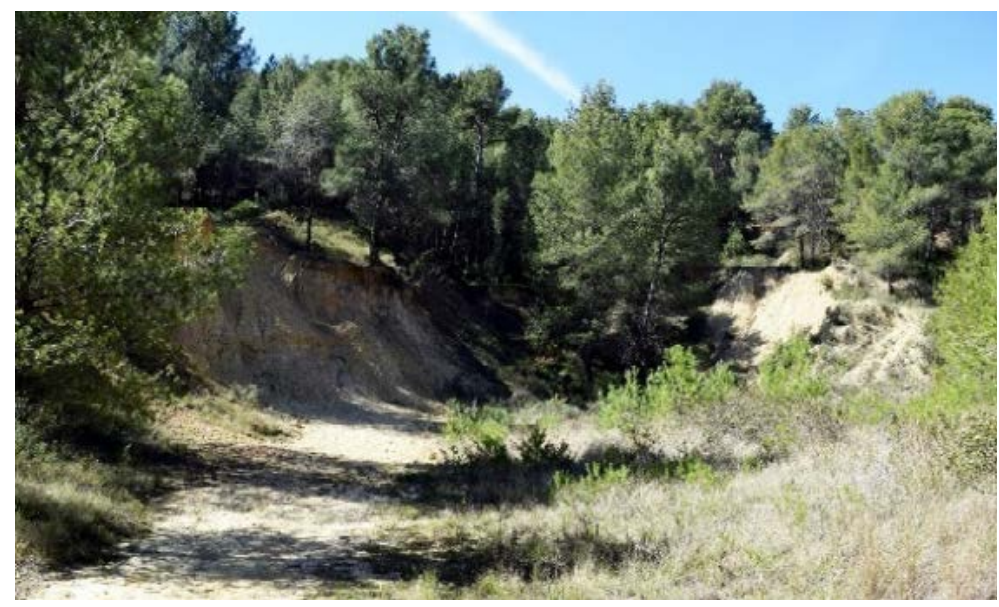

Figura 1. Mina de arcilla de San Vicente, Alcora, Castellón (España). Fuente: K. Lee.

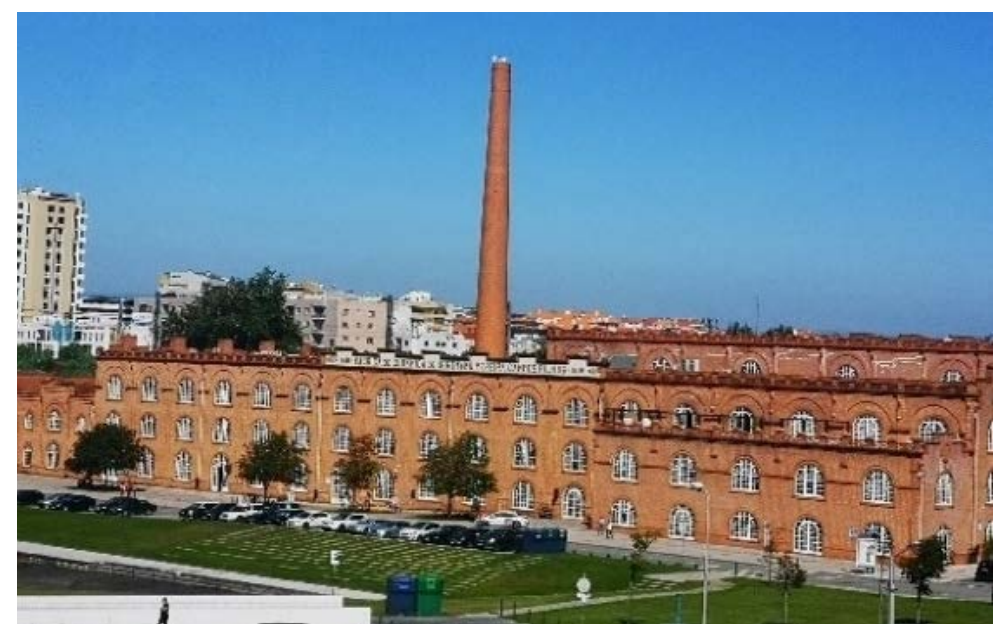

Figura 2. Antigua fábrica de cerámica de Jeronymo Pereira Campo, Aveiro (Portugal). Fuente: K. Lee.

Por otra parte, los residuos de cerámica también influyen en el paisaje. En los paisajes industriales de la cerámica se encuentran escombreras de piezas enterradas o cubiertas de tierra. En Bunwon-ri, Gwangju (Corea del Sur) donde se producían las porcelanas para la corte de la Dinastía Joseon, se localizan restos fracturados por el suelo sin dificultad (Figura 3). Un caso similar se produce en Gorge, donde Alfrey y Clark (2005) mencionaron que la industria cerámica dejó también su impresión en el paisaje a través de los desperdicios de alfarería y tejas. 
La producción de cerámica influye en el paisaje no solo a través de sus complejos industriales, sino también con sus productos finales. Las esculturas cerámicas o las instalaciones de cerámica en un espacio urbano, medio rural e incluso natural, añaden una belleza visual a su paisaje como han indicado Calaf y Fontal (2002) sobre los edificios decorados con azulejos o mosaicos. La combinación geométrica, original de la cultura árabe, ha devenido en diferentes gustos, y forma parte de patrimonio (Figura 4).

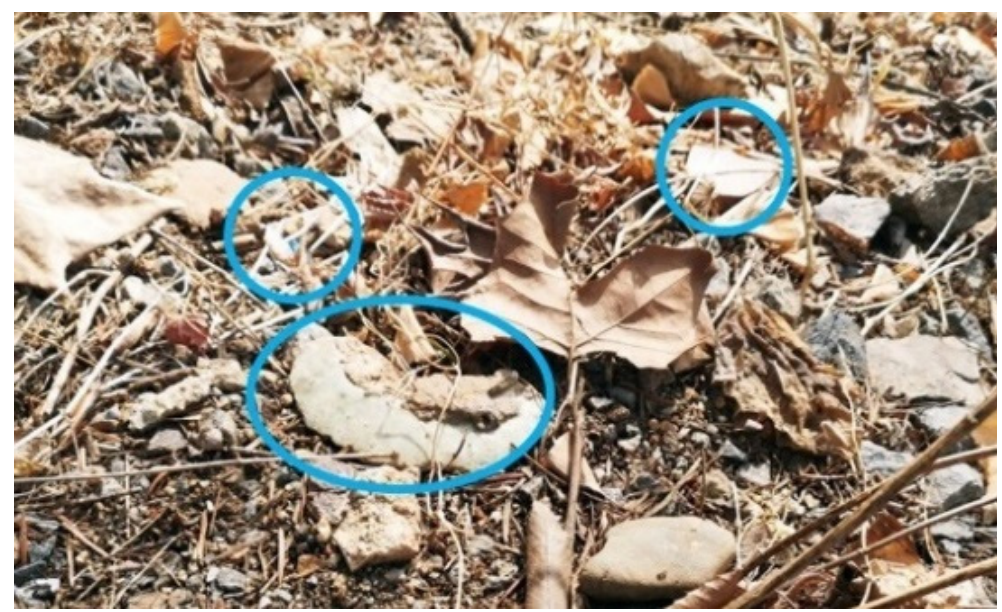

Figura 3. Residuos de cerámica alrededor del Museo de Baekja de Bunwon en Gwangju (Corea del Sur). Fuente: K. Lee.

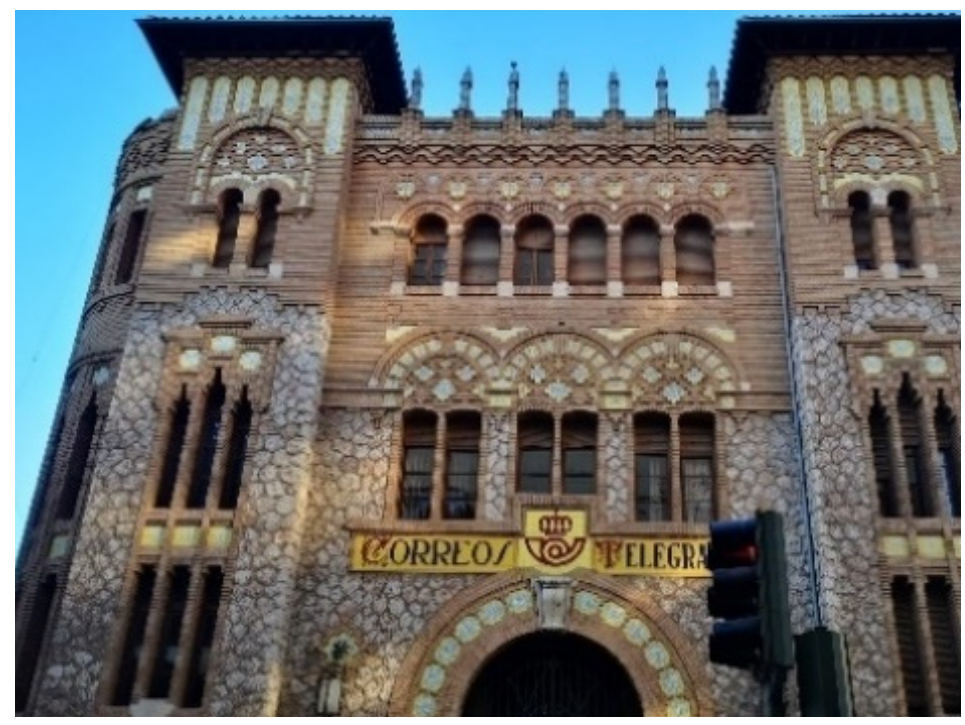

FIgura 4. Edificio de Correos decorado con azulejos en Castellón (España). Fuente: K. Lee. 


\subsection{Los valores educativos de la producción de cerámica}

La fabricación de cerámica contiene valores educativos transversales asociados a diferentes disciplinas. Desde un punto de vista geográfico, los lugares de fabricación de cerámica poseen el potencial para facilitar la comprensión de la relación que existe entre su localización y el desarrollo económico de una región y la vida de su población. Esto es, a través de la observación y el análisis de esta actividad humana en un territorio, se puede elaborar una perspectiva multifacética con la que es posible ver no solo la relación entre el entorno natural y las actividades humanas, sino también las huellas de estas actividades industriales marcadas en un paisaje.

Un paisaje cultural es un resultado visible y característico de una serie de actividades del ser humano que habita, gestiona y también disfruta un espacio: "Nacemos, vivimos y morimos en algún paisaje, este paisaje nos identifica y nos aporta sentido de pertenencia a una parte del territorio" (Liceras Ruiz, 2018a, p. 29). Es decir, si se lo considera desde un sentido amplio, se puede decir que un paisaje cultural proyecta los valores sociales y los paradigmas arraigados entre los miembros de una sociedad y también representa su identidad común (Martínez de Pisón, 2010; Álvarez Munárriz, 2011; García de la Vega. 2011).

Los valores del patrimonio industrial y del paisaje industrial se recogen en la Carta De Nizhny Tagil Sobre El Patrimonio Industrial de 2003, en la que se establece que "los edificios y las estructuras construidos para actividades industriales, los procesos y las herramientas utilizadas y las localidades y paisajes donde se han ubicado, así como todas sus otras manifestaciones tangibles o intangibles, poseen una importancia fundamental" (p. 1).

Estos valores deben relacionarse con los cambios sociales a los que nos enfrentamos en la actualidad. En otras palabras, debemos considerar el paisaje industrial como un patrimonio cultural que nos ha llegado desde este período postindustrial. Hay que ver qué papel juegan las antiguas fábricas dentro de un entorno natural o urbano, y qué significan desde el punto de vista histórico y espacial. En este contexto, en cuanto a su uso didáctico, Hernández Carretero concluye que "el uso del paisaje cultural como recurso didáctico nos permite reflexionar sobre la enseñanza de dos de los aspectos fundamentales de las Ciencias Sociales, el Espacio y el Tiempo" (Hernández Carretero, 2010, p. 167).

La implicación del museo en la gestión, el cuidado y la protección del paisaje quedó propuesta en la Carta de Siena por el ICOM (2014) que, junto con la UNESCO, realizó una recomendación orientada a la educación destinada a preservar el patrimonio y promover la diversidad cultural y natural. Teniendo en cuenta estas características, además de la educación histórica o artística, los museos y los paisajes culturales en los 
que se encuentran son especialmente adecuados para llevar a cabo la educación con los contenidos de la Geografía, que con sus precisiones metodológicas debería completar las orientaciones expresadas en el currículum (García de la Vega, 2011).

\section{EL MUSEO Y SU PAPEL COMO INSTITUCIÓN EDUCATIVA}

En la actualidad, el papel de los museos como instituciones educativas ha sido definido tanto por instituciones internacionales como nacionales. El ICOM define que un museo es una institución que "expone el patrimonio tangible e intangible de la humanidad y de su entorno para la educación, el estudio y el deleite" (ICOM, 2017, p. 3). En la Ley Orgánica 16/1985, de 25 de junio, del Patrimonio Histórico Español, también se recoge el papel educativo del museo: "Son Museos las instituciones de carácter permanente que adquieren, conservan, investigan, comunican y exhiben para fines de estudio, educación y contemplación conjuntos y colecciones de valor histórico, artístico, científico y técnico o de cualquier otra naturaleza cultural".

Por su propia naturaleza, la educación museística ha sido reconocida al menos desde principios del siglo XIX (Hooper-Greenhill 1991; citado en Hein, 2006). De acuerdo con Hooper-Greenhill (2007), la educación museística tiene un gran potencial dependiendo la naturaleza, el objetivo y el entorno de cada museo, puesto que el aprendizaje en los museos presenta más libertad en sus opciones que el aprendizaje tradicional. Una ventaja que proporcionan los museos es la participación activa de los visitantes: como no hay un examen o una evaluación de la educación en el museo, éstos no dudan en intentar nuevas experiencias (Huerta, 2010). Así, los educadores del museo pueden acercarse a diferentes temas que puedan estimular la curiosidad de los participantes.

En fechas recientes muchos de estos lugares patrimoniales han sido musealizados y en ellos se realizan programas educativos y proyectos de divulgación cultural destinados a un público general y a grupos escolares. Los museos, que se ubican en los sitios de producción cerámica ofrecen diversas actividades educativas utilizando la colección, junto al entorno.

La investigación sobre los museos industriales como un recurso educativo ya ha sido abordada en el trabajo de Sebastiá y Blanes (2001): "el museo industrial supone un recurso extraordinario para crear un conocimiento significativo a partir del entorno, capaz de modificar las ideas previas y construir nuevos conocimientos (p.434). Sin embargo, en muchos lugares donde la cerámica es la principal industria, el tema de los museos de estas zonas se ha centrado más en aspectos históricos o artísticos, denominándose a menudo "Museo histórico" o "Museo de cerámica". Dada la importancia de esta industria en la economía, la cultura y la sociedad de estos lugares, estos museos, tal y como ha señalado Artero Gonell refiréndose a la Real Fábrica de Cerámica de Alcora, 
pueden desempeñar un papel proactivo como símbolo de la comunidad que sirva para aumentar la cohesión social (Artero Gonell, 2019). En el Museo de Cerámica de Alcora se ofrece una visita guiada llamada "Ruta de la cerámica". En ella se incluyen diferentes elementos cerámicos e históricos, por ejemplo, la Capilla de Marco, que está decorada por azulejos del Barroco dentro del casco antiguo, además de la colección del propio museo. Por eso, se puede considerar que el papel de estas instituciones como museos locales va más allá de ser simples museos de colecciones de cerámica o museos de historia de la cerámica.

\subsection{Walking tour: una estrategia de aprendizaje para las actividades museísticas}

Los métodos y técnicas para la educación museística deberían considerar varios factores, como el perfil de los visitantes, el grupo destinatario del programa, los recursos del museo, etc. Van Veldhuizen (2017) ha sistematizado las metodologías para la educación museística y patrimonial en dieciocho categorías, siendo una de ellas las visitas guiadas, el método didáctico más antiguo y más popular en los museos. La autora dividió este método en cinco variantes, y una de ellas es "Caminar (por la ciudad)" (City) walk.

Este planteamiento didáctico se emplea frecuentemente en forma de recorridos por la ciudad por empresas privadas o por los ayuntamientos, pero también en museos que inculyen así la visita a diferentes elementos del patrimonio histórico de la región (Schlereth, 2016). Por ejemplo, entre 1960 y 1980, el Museum of the City of New York ofreció un programa llamado Sunday walking tours destinado a los ciudadanos neoyorkinos y a los turistas. Se trata de ofrecer una experiencia única conducida por guías expertos que ofrecen la descripción de los detalles históricos y arquitectónicos de los barrios de la ciudad (Chapin, 2019). Desde 2013, en el Museo de Hanseong Baekje de Seúl [서울 한성 백제박물관] se realiza un walking tour para los grupos familiares, con el propósito de descubrir la historia y cultura de la antigua capital de Baekje y visitar su patrimonio histórico (Museo de Hanseong Baekje, 2020)

A menudo, en las actividades museísticas los aspectos geográficos no son especialmente destacados, sobre todo en comparación con los de otras disciplinas. Por ejemplo, el Museo de Baekja de Bunwon [분원 백자자료 관] de Gwangju (Corea del Sur) se ubica sobre los antiguos talleres reales de porcelana de la Dinastía de Joseon. Este museo ofrece un gran potencial para realizar actividades de enseñanza geográfica relacionadas con la localización de los talleres y su entorno natural, además de los cambios del paisaje. Sin embargo, el museo solamente ofrece paneles informativos sobre este tema. (Figuras 5 y 6 ). 

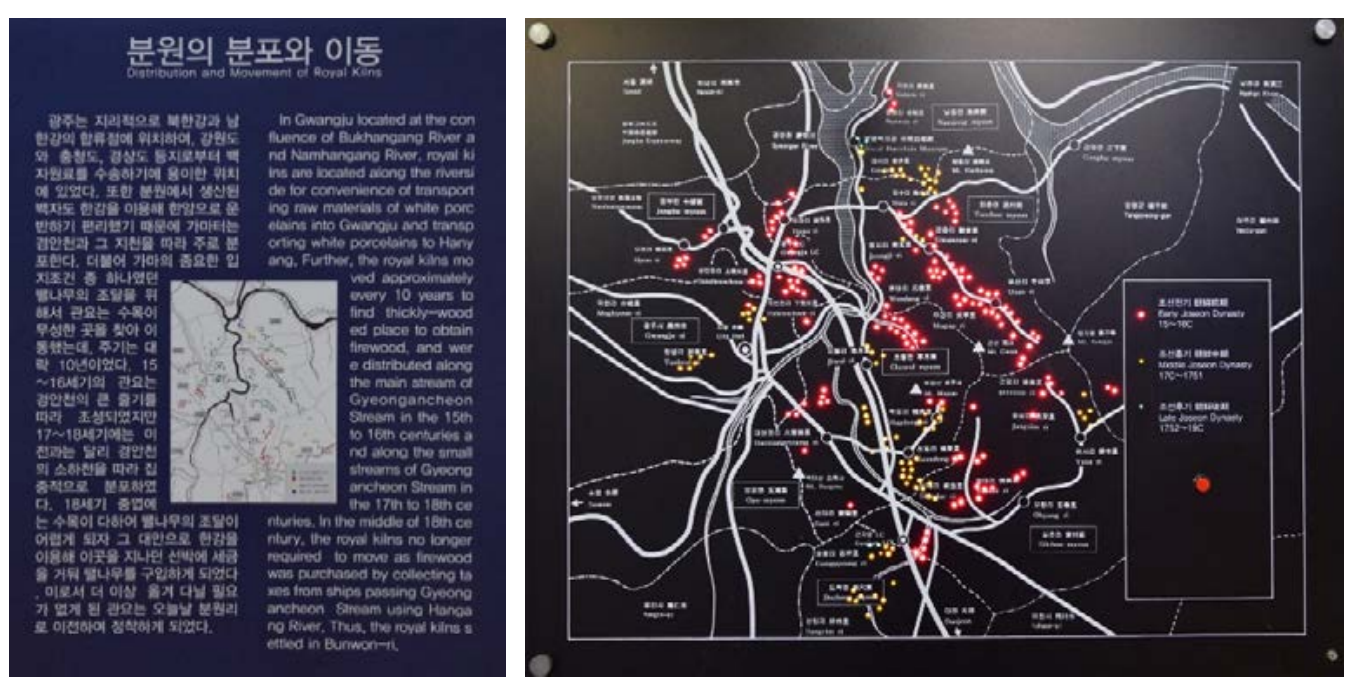

FiguRAs 5 y 6 . Paneles informativos con contenidos geográficos de los talleres de cerámica en el Museo de Baekja de Bunwon (Corea del Sur). Fuente: K. Lee.

Caminar por la ciudad, medio rural o también por la naturaleza - (city/ suburb/ nature) walk - se enmarca dentro del contexto de los itinerarios didácticos para la enseñanza geográfica, puesto que ofrece la oportunidad de observar y sentir los elementos de un espacio y analizar la relación entre ellos (Sebastiá Alcaraz y Tonda Monllor, 2000; García de la Vega, 2004; Liceras Ruiz, 2018b). Es decir, es un método especialmente adecuado en el caso de los paisajes industriales, que permite transmitir los conocimientos geográficos al público de una forma precisa que a menudo aparece alterada debido a las generalizaciones de los libros de texto (Sebastía Alcaraz y Blanes Nadal, 2010). Hommand (2018) señala que este método oferece a los estudiantes la oportunidad para que puedan pensar geográficamente. Considerado como una extensión de las oportunidades de aprendizaje, García de la Vega (2019) señala que "el itinerario didáctico proporciona la adquisición de diversas destrezas geoespaciales, que forman parte del aprendizaje para toda la vida" (p. 65).

Dentro de los itinerarios didácticos, hay diferencias en sus objetivos y formato dependiendo del contexto educativo en el que se realicen; es decir, se puede apilicar de manera diferente según el tipo de institución o el entorno educativo. De acuerdo con la definición de Coombs y Ahmed (1974) de la educación formal, no formal e informal (Tabla 1), el itinerario didáctico dentro de la educación formal y el itinerario didáctico de la educación no formal, como el walking tour realizado por el museo para un público abierto, muestran diferencias en el propósito, el objetivo y el método de la educación. 


\begin{tabular}{|c|c|c|}
\hline Educación formal & Educación no formal & Educación informal \\
\hline $\begin{array}{l}\text { Sistema educativo } \\
\text { altamente } \\
\text { institucionalizado, } \\
\text { cronológicamente } \\
\text { graduado y estructurado } \\
\text { jerárquicamente. } \\
\text { Desde la escuela primaria } \\
\text { hasta la universidad. }\end{array}$ & $\begin{array}{l}\text { Cualquier actividad } \\
\text { educativa organizada, } \\
\text { sistemática, realizada } \\
\text { fuera del marco del } \\
\text { sistema formal. } \\
\text { Grupos particulares de } \\
\text { la población, adultos y } \\
\text { niños. }\end{array}$ & $\begin{array}{l}\text { Desorganizado y a menudo } \\
\text { no sistemático. } \\
\text { Proceso de toda la vida } \\
\text { mediante el cual cada } \\
\text { persona adquiere y } \\
\text { acumula conocimientos, } \\
\text { habilidades y modos } \\
\text { de discernimiento de } \\
\text { experiencias diarias y } \\
\text { su relación con al medio } \\
\text { ambiente. }\end{array}$ \\
\hline
\end{tabular}

TABLA 1. Distinciones entre los tres modos de educación por Coombs y Ahmed (1974).

Fuente: Elaboración propia.

La clave para distinguir el tipo de educación consiste en el grado de estructuración, referido a la flexibilidad en las metas y la planificación de la estructura de las actividades (Livingstone, 2006). En este sentido, la educación no formal es menos jerárquica que la educación formal, y depende más del trabajo autónomo del estudiante que la educación formal. En esta, los conocimientos ya están hechos y acabados, por tanto, no es necesario hacer un esfuerzo voluntario para construirlos (Asensio, 2001; Asensio y Pol, 2001). Sin embargo, los participantes en las actividades de la educación no formal pueden aprender del educador que han elegido libremente en un sistema relativamente abierto que apunta a una educación en y a través de la vida (Livingstone, 2001; Rogers, 2004). Además, dado que se realiza en lugares como museos, bibliotecas o bien centros culturales, los participantes pueden adquirir un aprendizaje contextual a través de la experiencia de la interacción con la sociedad (Rogers, 2004, Choi, 2011). A todo ello habría que añadir que los contenidos y los objetivos de cada programa son más flexibles.

Por esta razón, el walking tour ofrecido dentro de la educación no formal tiene unas características distintas al itinerario didáctico. Dado que la educación en museos es parte de la educación permanente, las personas de diferentes edades y entornos socioculturales pueden participar juntas (Lebrún Aspíllaga, 2015). Esto se puede considerar como otra ventaja del walking tour del museo, ya que proporciona al púbico general una experiencia de itinerario didáctico construido con los contenidos de la Geografía, tales como los diferentes tipos de paisaje, el clima, la vegetación.

En el caso del walking tour, la oferta del museo para los centros escolares cambia las condiciones del aprendizaje formal. Así, el mediador didáctico del museo resulta diferente al docente habitual y el alumnado mezcla edades y regiones de procedencia. A 
través de esto, los estudiantes pueden tener una oportunidad de aprender sin preocuparse por las pruebas o las notas, comunicarse con nuevas personas y ampliar su perspectiva. Se entiende que los itinerarios didácticos dentro de la educación no formal tienen un papel de complementar y reforzar los conocimientos que han aprendido durante la educación formal (Jerez García, 2012; Pérez Melgar y Morón Monge 2016). Por lo tanto, a través del walking tour, los participantes identifican distintos tipos de paisajes y los elementos característicos, así como la relación entre la sociedad local y la industria que han aprendido en la escuela. Los educadores de los museos también tienen la ventaja de poder utilizar de manera flexible los contenidos de diferentes cursos escolares en la selección y organización del programa.

Otra característica positiva está en la espontaneidad de los participantes. Estos están interesados de forma voluntaria en lo que ofrece el museo y en participar en los posibles cursos formativos que este pueda ofrecer, listos para aprender desde el primer momento. (Byeon, 2008) En este contexto, también se encuentran diferencias entre la educación informal que ofrecen los museos en relacion con el objetivo y el papel del museo como un insticución esencial y activa de educación en una comunidad, como señaló Hein (2006): "Museum education converges with social responsibility: the social service that museums, as public institutions, provide is education. (p. 349)".

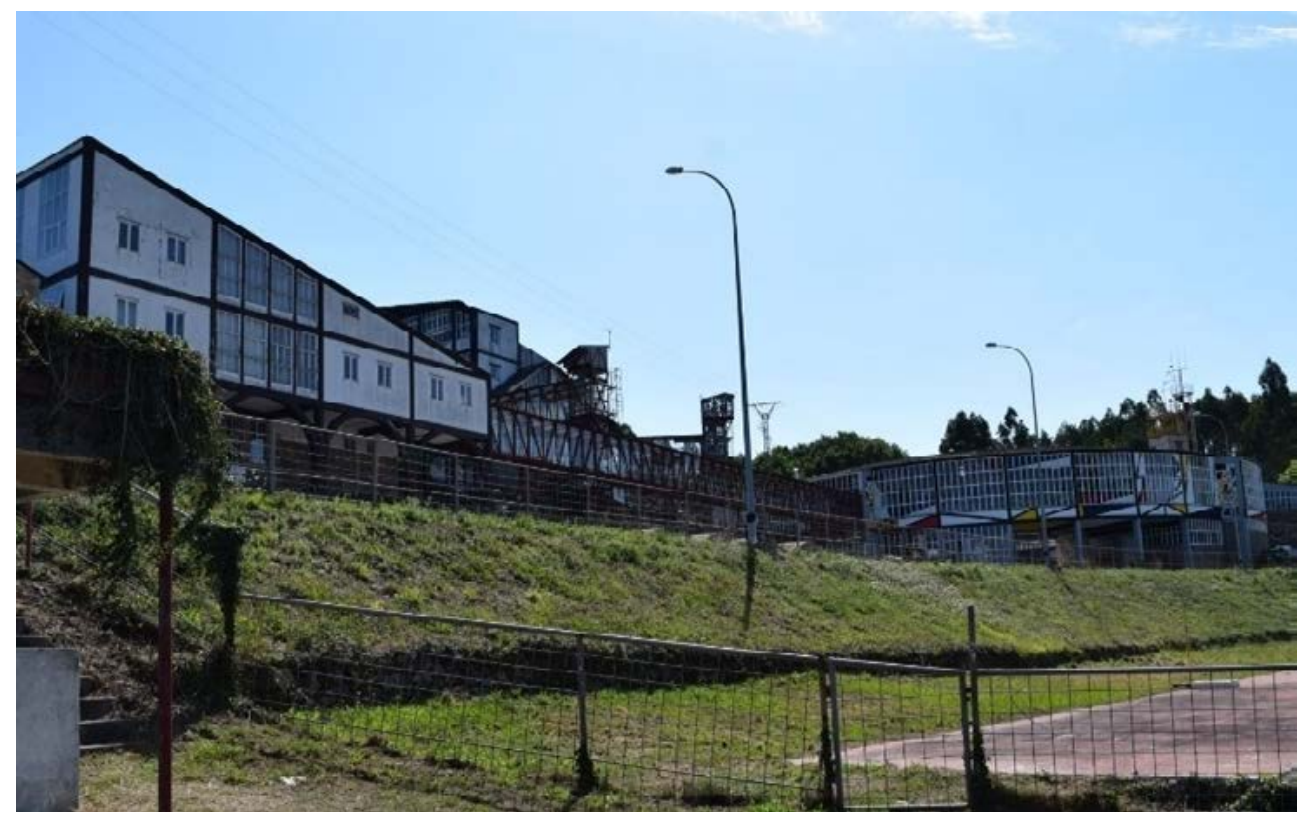

Figura 7. Actual fábrica de Cerámica de Sargadelos, Lugo. Fuente: P. Ordás. 


\section{UN POTENCIAL DIDÁCTICO DEL ÁMBITO MUSEÍSTICO: CAMIMAR POR SARGADELOS}

La fábrica de Cerámica de Sardelos, localizado en Cervo (Lugo), ha sido declarada Bien de Interés Cultural (2014) (Figura 7) y se sitúa en el entorno natural del río Xunco. En Julio de 2020 la actual fábrica abrió su propio museo que ofrece una visita guiada a la galería y al edificio de producción, donde se explica la historia de Sargadelos y el proceso de fabricación. La antigua fábrica de fundición y de loza de Sargadelos (Antiguo Complejo Siderúrgico y Cerámico de Sargadelos) se sitúa en las inmediaciones de la fábrica actual y también fue declarado Bien de Interés Cultural en 1972 (Figura 8). Algunas partes del recinto de la antigua fábrica están musealizadas con señales y paneles informativos. También se puede hacer una corta ruta de senderismo para visitar la presa del río Xunco que proporcionaba energía a la antigua fábrica. En la actualidad, el Museo Histórico de Sargadelos, dependiente de la Diputación de Lugo, se encuentra en el edificio original de la Casa de la Administración, integrada en el Conjunto Histórico Artístico de Sargadelos (Figura 9). Este museo cuenta con una exposición permanente sobre la historia de la fábrica a través de su colección fotográfica, piezas allí producidas, grabados, etc. Esta institución puede jugar un papel esencial como trasmisor de educación gracias a la riqueza de los recursos geográficos e históricos y las relaciones orgánicas entre los elementos del paisaje de este lugar.

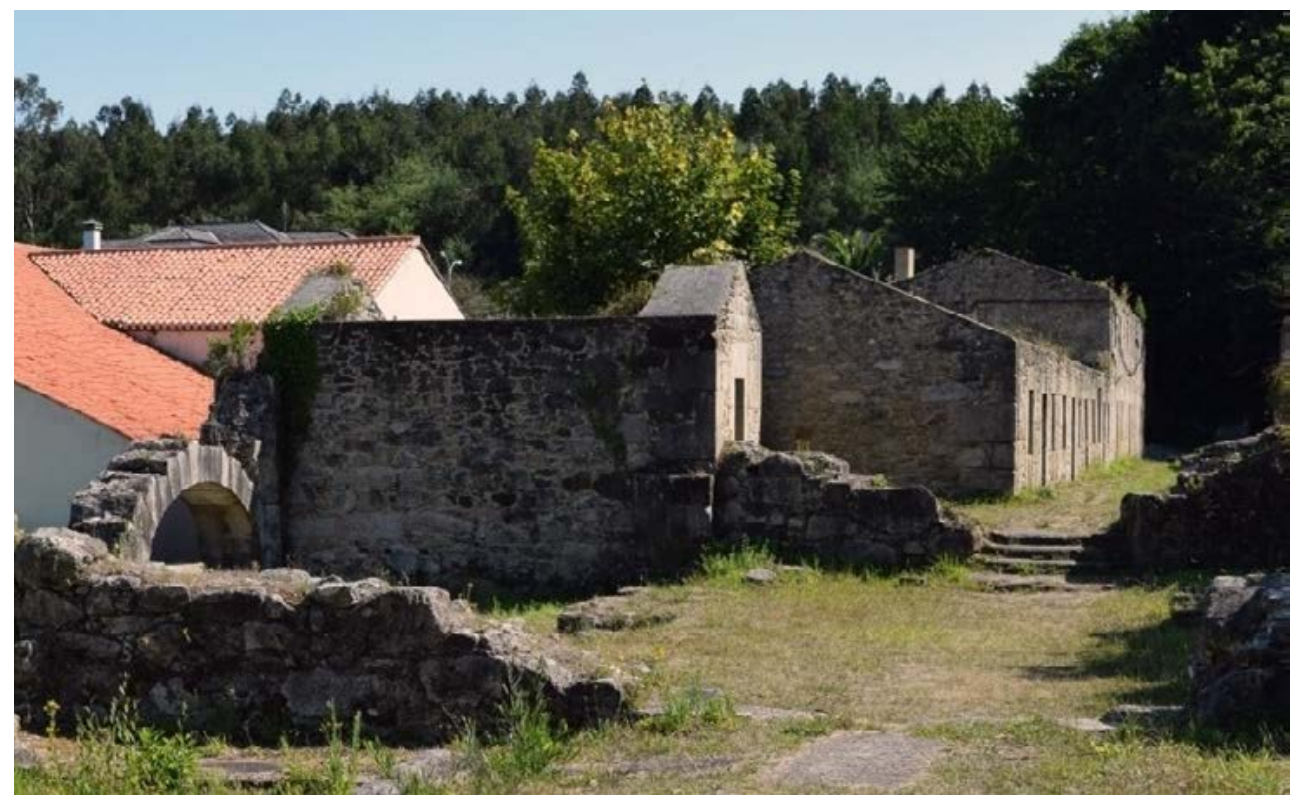

Figura 8. Antigua fábrica de Cerámica de Sargadelos, Lugo. Fuente: P. Ordás. 


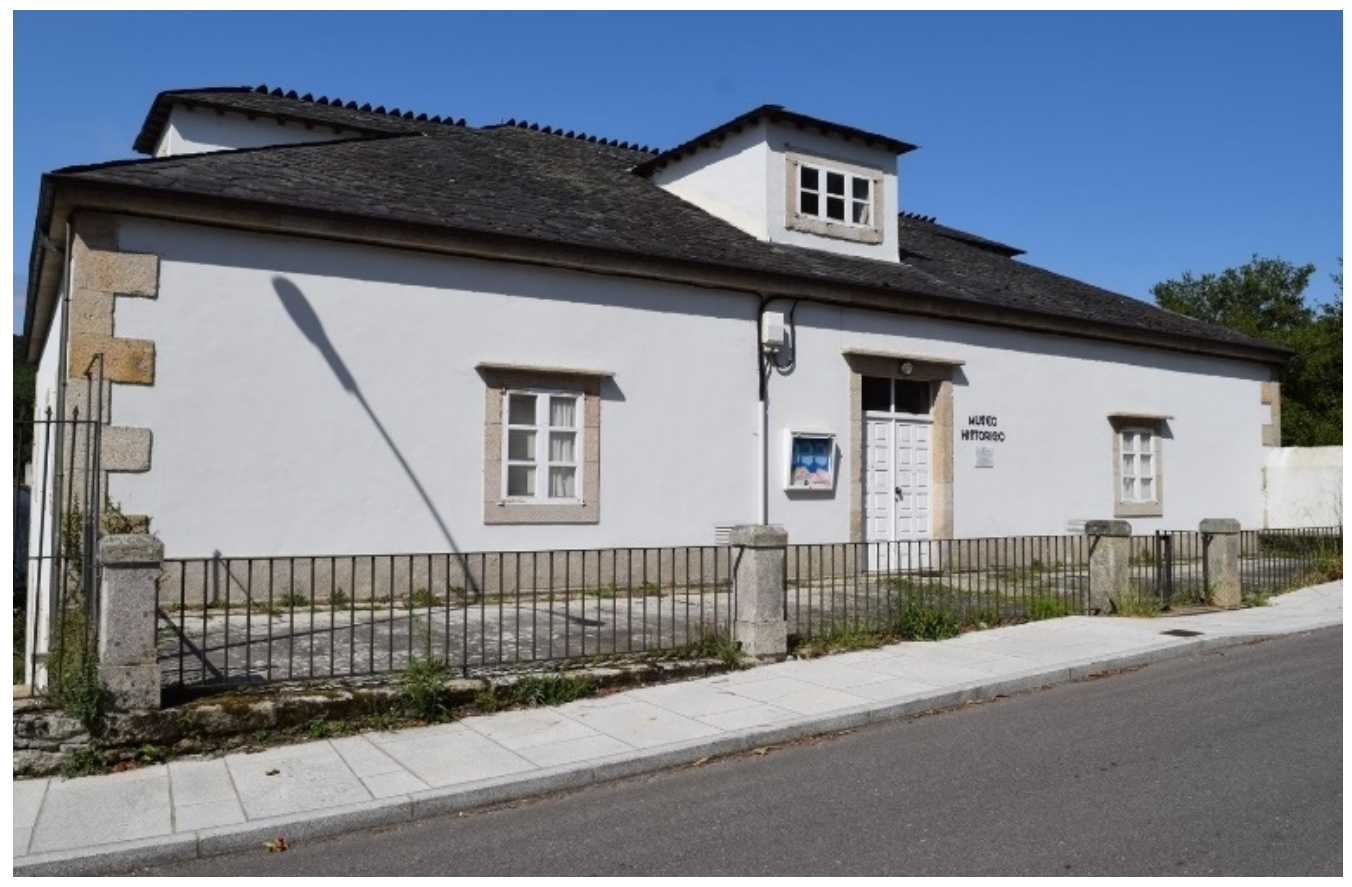

FIgura 9. Museo Histórico de Sargadelos, Lugo. Fuente: P. Ordás.

\subsection{Localización y contexto histórico}

En 1791 Antonio R. Ibáñez obtenía el permiso para comenzar la construcción de su industria siderúrgica en el lugar de Santiago de Sargadelos (Lugo). El emplazamiento, en el municipio de Cervo, resultaba especialmente atractivo gracias a su situación entre los dos puertos más importantes de Galicia en el Cantábrico: Ribadeo y Viveiro. Esta ubicación no solo facilitaba el transporte de los productos acabados, sino que además contaría con la cercanía de recursos naturales esenciales, como la madera de los bosques para la obtención de combustible o la energía hidráulica que proporcionaría el río Xunco (Prado Gómez, 1993) (Figuras 10 y 11). Ibáñez habría obtenido, además, la exclusividad para la explotación de las tierras refractarias de la zona, esenciales para la producción de cerámica. 


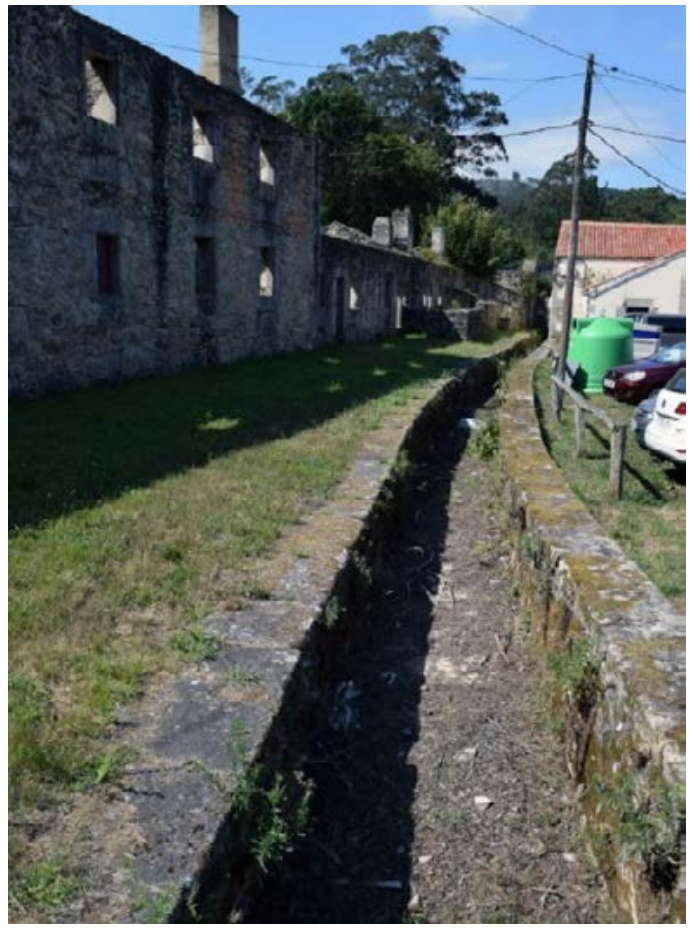

Figura 10. Caz de enlace al río Xunco. Fuente: P. Ordás.

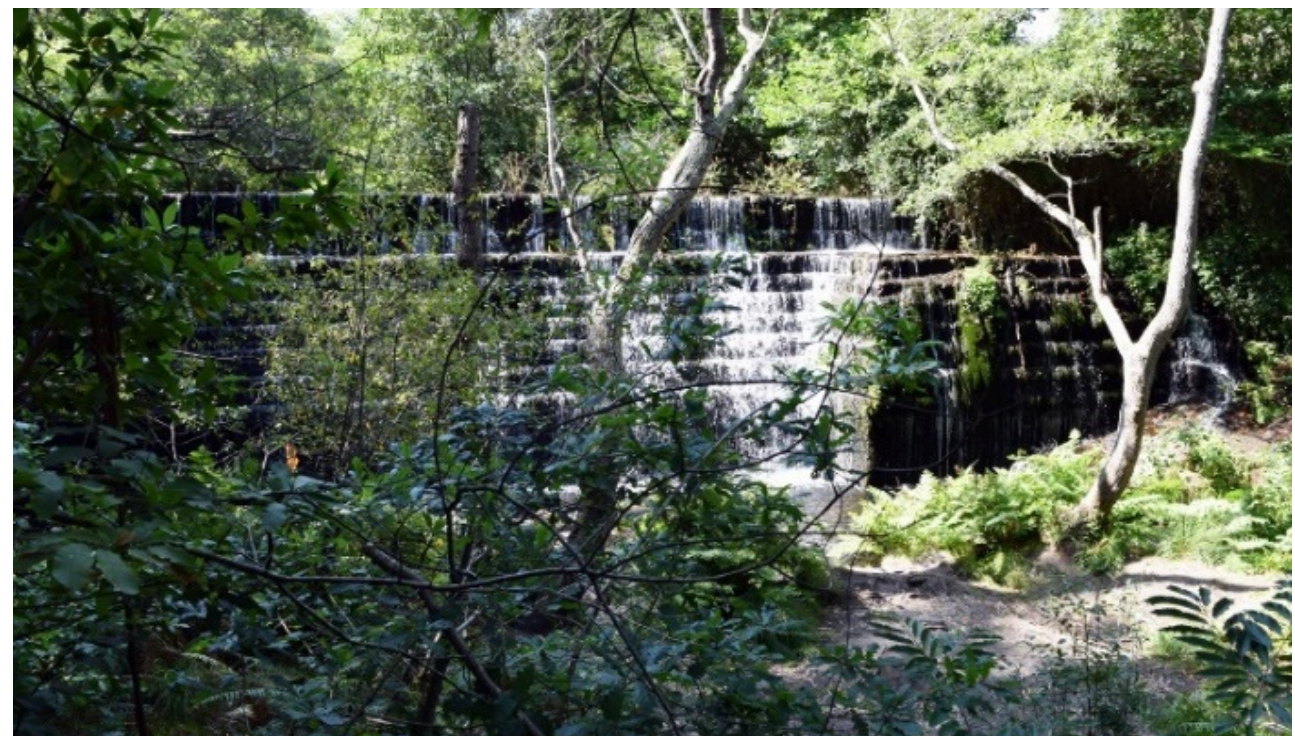

Figura 11. Presa en el río Xunco. Fuente: P. Ordás. 
El plan original del industrial asturiano no consistía en la fabricación de elementos de cerámica, sino de potes de metal como los que se importaban desde Burdeos. En agosto de 1792, comenzó la construcción de un canal y un dique sobre el río Xunco. Estas intervenciones en el paisaje fueron los primeros cambios sobre su fisionomía, pues continuaron los edificios necesarios para la producción industrial: carboneras, hornos, almacenes y talleres. En 1793, comenzaba la fundición de hierro, combinando la producción de potes de metal con la munición para el ejército. Las edificaciones se proyectaron como pabellones independientes comunicados a través de caminos, siendo el canal el eje vertebrador del entorno arquitectónico. Este modelo arquitectónico corresponde al más avanzado de las Reales Fábricas frente a otros modelos más antiguos, como la Real Fábrica de Cerámica de Alcora, organizada alrededor de un patio central. (Bas Ordóñez, 2010; Díaz-Maroto, 2019).

Se tiene constancia de la producción de cerámica en Sargadelos al menos desde 1804. El principal objetivo de Ibáñez en el campo de la cerámica era el mismo que en el de la producción siderúrgica. Esto es, se trataba de ofrecer un producto de características similares a los importados a un precio más bajo. Francia fue la inspiración de la producción de potes e Inglaterra proporcionó los estilos de producción de cerámica. En concreto se imitará el estilo propio de Bristol y producirá loza de tipo "creamware" (Martul Vázquez y Varela Zapata, 2009). En 1813 recibe el título honorífico de Real Fábrica de Loza y Porcelana, si bien la producción de porcelana nunca llegó a ser comercializada en esta primera fase.

Tras la Guerra de Independencia la fábrica sufrió sucesivas ampliaciones, añadiéndose altos hornos y hornos de calcinación, y pasando por diversas manos y asociaciones, si bien la producción de municiones y la demanda siderúrgica había caído de forma evidente, ya que la fábrica no había sido modernizada y no podía competir con los productos que se importaban. En 1875 el último propietario decide cerrar las puertas de la fábrica en el complejo de Santiago de Sargadelos, y en 1903 abre en Burela "Cerámica de Sargadelos", una empresa creada aprovechando la maquinaria de la fábrica original, produciendo únicamente material refractario y abandonando la elaboración de loza (Pérez Vázquez, 2011).

La actual fábrica nacerá dentro del proyecto del Laboratorio de Formas de Galicia, creado en 1963 por Luis Seoane e Isaac Díaz Pardo. La familia de Díaz Pardo, propietaria de Cerámicas do Castro será el principal accionista para la nueva Cerámica de Sargadelos, establecida formalmente en 1968, aprovechando la cercanía de una mina de caolín, inaugurando en 1970 las instalaciones construidas por el arquitecto Andrés Fernández-Albalat (Volkova, 2017; Díaz-Maroto, 2019).

El primitivo complejo industrial en Santiago de Sargadelos sufrió un estado de abandono desde finales del siglo XIX y los edificios presentan diferentes grados de conservación: el 
palacio es una vivienda privada y algunas de las instalaciones, como el taller de mecánica, se han reutilizado salvándolas así del derrumbe. Para evitar estos problemas, Martul Vázquez ya proponía la musealización de Sargadelos (Martul Vázquez, 1999). En 2015, la Consellería de Cultura, Educación y Ordenación Universitaria declaró la Fábrica de Cerámica de Sargadelos ligada al Laboratorio de Formas Bien de Interés Cultural.

\subsection{Orientaciones metodológicas para un walking tour}

Como se explicó en el capítulo anterior, un espacio geográfico puede ser observado desde múltiples ángulos a través de la metodología de "caminar". Se puede ver desde el aspecto histórico, que es el que más común, o desde el aspecto geográfico, teniendo en cuenta las diversas relaciones que se establecen entre un espacio y la industria, por ejemplo la adecuación del tipo de industria con las materias primas disponibles o la facilidad para su transporte a través de vías naturales, como ríos, etc.

En este contexto, los objetivos principales de esta propuesta son:

- Conocer y entender los diferentes paisajes que se pueden encontrar en un espacio geofráfico a través de la observación y los sentidos.

- Comprender que la industria de cerámica modifica y genera el paisaje.

- Entender la relación entre la industria y las características geográficas de una región.

- Asociar el paisaje cultural con la colección de museo y saber que es algo que se debe preservar.

- Reconocer el valor del aprendizaje continuo a través de las actividades museísicas con otras personas.

Esta propuesta consiste en los siguientes tres pasos: 1 . El educador debe tener pleno conocimiento del lugar, 2. Realizar una actividad interactiva con suficiente comunicación con los participantes, y 3. Dar tiempo a los participantes para utilizar plenamente los cinco sentidos en actividades al aire libre.

En cuanto al segundo paso, una mera explicación puede ser percibida como una simple transferencia de conocimiento que lleve a que los participantes pierdan su interés. Puesto que es necesario atraer la curiosidad e interés de los visitantes a las exhibiciones y estimular el deseo de adquirir conocimiento (Tilden, 1977) se pueden aplicar diferentes recursos, tales como la técnica de preguntas-respuestas o el juego de pistas. A través de este proceso de interacción, los participantes hacen preguntas y encuentran respuestas respondiendo al educador o a ellos mismos, basándose en el conocimiento ya construido y también pasan por el proceso de observar y reconocer los elementos del paisaje mientras caminan por la ruta. A este respecto, se puede decir que este recorrido articipativo muestra un aspecto de autoaprendizaje y se basa en la educación constructivista del museo (Hein, 1998; Jung, 2018). 
Estas actividades deben ajustarse al perfil del público, es decir, el contenido de la actividad debe coincidir con las capacidades intelectuales, el nivel físico y de conocimientos y el interés de los participantes (Asensio y Pol, 2001 y 2008; Serrat Antolí, 2007; Montenegro Valenzuela, 2011).

Respecto al tercer paso, se trata de un aspecto importante y se debe dar el suficiente tiempo para la plena experimentación sensorial del paisaje. Con la adaptación de la tecnología de realidad virtual, aumentada o bien mixta en el ambito museístico, ya es posible realizar los recorridos "al aire libre" dentro de los museos. Sin embargo, estas experiencias audiovisuales no pueden sustituir a la experiencia directa y única del aire libre (Tafalla, 2015; Liceras Ruiz, 2018b).

\subsection{Contenidos de la actividad}

El contenido de esta propuesta dirigida a los estudiantes de educación secundaria debe encontrar su base en el currículo. Esta región puede proporcionar una amplia gama de contenido educativo pues permite centrarse en los contenidos geográficos relacionados con el currículo de Geografía e Historia de Educación Secundaria Obligatoria y Geografía de Bachillerato. Los contenidos curriculares de Geografía se relacionan con los hitos elegidos de la ruta establecida desde el Museo Histórico hasta la fábrica actual de Sargadelos (Tabla 2).

\begin{tabular}{|c|c|c|c|}
\hline \multirow{2}{*}{ Paradas clave } & \multirow{2}{*}{$\begin{array}{l}\text { Posibles contenidos } \\
\text { geográficos }\end{array}$} & \multicolumn{2}{|c|}{$\begin{array}{l}\text { Bloques del currículo especialmente } \\
\text { relacionados con walking tour }\end{array}$} \\
\hline & & Etapa & Bloque \\
\hline \multirow{3}{*}{$\begin{array}{c}\text { Museo histórico de } \\
\text { Sargadelos } \\
\text { (punto 1) }\end{array}$} & \multirow{4}{*}{$\begin{array}{l}\text { Información geográfica } \\
\text { e histórica básica sobre } \\
\text { la zona y la industira. }\end{array}$} & $1^{\mathrm{o}}, 2^{\mathrm{o}}, 3^{\mathrm{o}} \mathrm{de}$ & 1. El medio físico \\
\hline & & ESO & 2. El espacio humano \\
\hline & & $4^{\mathrm{o}} \mathrm{de} \mathrm{ESO}$ & 3. La Revolución Industrial \\
\hline $\begin{array}{l}\text { - Casa de la } \\
\text { Administración }\end{array}$ & & $\begin{array}{l}2^{\circ} \text { de } \\
\text { Bachillerato }\end{array}$ & $\begin{array}{l}\text { 1. La Geografía y el estudio del } \\
\text { espacio geográfico }\end{array}$ \\
\hline \multirow{3}{*}{$\begin{array}{l}\text { Las antiguas } \\
\text { fábricas de } \\
\text { fundición y loza } \\
\text { (punto 2) }\end{array}$} & \multirow{3}{*}{$\begin{array}{l}\text { Paisaje construido } \\
\text { por la industria en la } \\
\text { naturaleza. }\end{array}$} & $1^{\mathrm{o}}, 2^{\mathrm{o}}, 3^{\mathrm{o}} \mathrm{de}$ & 1. El medio físico \\
\hline & & ESO & 2. El espacio humano \\
\hline & & & $\begin{array}{l}\text { 1. La Geografía y el estudio del } \\
\text { espacio geográfico }\end{array}$ \\
\hline \multirow{2}{*}{$\begin{array}{l}\text { - Hornos } \\
\text { - Carbonera }\end{array}$} & \multirow{2}{*}{$\begin{array}{l}\text { Localización de } \\
\text { industria. }\end{array}$} & $\begin{array}{l}2^{\circ} \text { de } \\
\text { Bachillerato }\end{array}$ & $\begin{array}{l}\text { 5. Los paisajes naturales y las } \\
\text { interrelaciones naturaleza-sociedad }\end{array}$ \\
\hline & & & $\begin{array}{l}\text { 8. Las fuentes de energía y el } \\
\text { espacio industrial }\end{array}$ \\
\hline
\end{tabular}




\begin{tabular}{|c|c|c|c|}
\hline \multirow{2}{*}{ Paradas clave } & \multirow{2}{*}{$\begin{array}{l}\text { Posibles contenidos } \\
\text { geográficos }\end{array}$} & \multicolumn{2}{|c|}{$\begin{array}{l}\text { Bloques del currículo especialmente } \\
\text { relacionados con walking tour }\end{array}$} \\
\hline & & Etapa & Bloque \\
\hline \multirow{6}{*}{$\begin{array}{l}\text { Canal - Presa del } \\
\text { río Xunco } \\
\text { (punto 3) }\end{array}$} & & $\begin{array}{l}1^{\circ}, 2^{\mathrm{o}}, 3^{\mathrm{o}} \mathrm{de} \\
\quad \mathrm{ESO}\end{array}$ & $\begin{array}{l}\text { 1. El medio físico } \\
\text { 2. El espacio humano }\end{array}$ \\
\hline & $\begin{array}{l}\text { Paisaje modificado } \\
\text { por los elementos de } \\
\text { industria. }\end{array}$ & $4^{\circ}$ de ESO & $\begin{array}{l}\text { 3. La Revolución Industrial } \\
\text { 1. La Geografía y el estudio del } \\
\text { espacio geográfico }\end{array}$ \\
\hline & Fuentes de energía & $\begin{array}{l}2^{\circ} \text { de } \\
\text { Bachillerato }\end{array}$ & $\begin{array}{l}\text { 4. La hidrografía } \\
\text { 5. Los paisajes naturales y las } \\
\text { interrelaciones naturaleza-sociedad }\end{array}$ \\
\hline & & & $\begin{array}{l}\text { 8. Las fuentes de energía y el } \\
\text { espacio industrial }\end{array}$ \\
\hline & & $1^{\mathrm{o}}, 2^{\mathrm{o}}, 3^{\mathrm{o}} \mathrm{de}$ & 1. El medio físico \\
\hline & & ESO & 2. El espacio humano \\
\hline \multirow{2}{*}{$\begin{array}{l}\text { Camino hasta la } \\
\text { fábrica actual } \\
\text { (punto } 4 \text { ) }\end{array}$} & $\begin{array}{l}\text { Caracteristicas de la } \\
\text { región. }\end{array}$ & & $\begin{array}{l}\text { 1. La Geografía y el estudio del } \\
\text { espacio geográfico }\end{array}$ \\
\hline & $\begin{array}{l}\text { (Vegetación, río } \\
\text { Xunco, medio rural e } \\
\text { industria) }\end{array}$ & $\begin{array}{c}2^{\circ} \text { de } \\
\text { Bachillerato }\end{array}$ & $\begin{array}{c}\text { 3. La diversidad climática y la } \\
\text { vegetación } \\
\text { 4. La hidrografía }\end{array}$ \\
\hline \multirow{7}{*}{$\begin{array}{l}\text { La fábrica actual de } \\
\text { cerámica } \\
\text { (punto 5) }\end{array}$} & & & $\begin{array}{l}\text { 5. Los paisajes naturales y las } \\
\text { interrelaciones naturaleza-sociedad }\end{array}$ \\
\hline & & $1^{\mathrm{o}}, 2^{\mathrm{o}}, 3^{\mathrm{o}} \mathrm{de}$ & 1. El medio físico \\
\hline & Paisaje industrial y & ESO & 2. El espacio humano \\
\hline & Pais & $4^{\circ}$ de ESO & $\begin{array}{c}\text { 10. La relación entre el pasado, el } \\
\text { presente y el futuro a través de la } \\
\text { Historia y la Geografía }\end{array}$ \\
\hline & los objetos de cerámica & & $\begin{array}{l}\text { 1. La Geografía y el estudio del } \\
\text { espacio geográfico }\end{array}$ \\
\hline & $\begin{array}{l}\text { Comparación entre } \\
\text { el ámbito que crea } \\
\text { la fábrica antigua y }\end{array}$ & $\begin{array}{c}2^{\circ} \text { de } \\
\text { Bachillerato }\end{array}$ & $\begin{array}{l}\text { 5. Los paisajes naturales y las } \\
\text { interrelaciones naturaleza-sociedad }\end{array}$ \\
\hline & actual. & & $\begin{array}{l}\text { 8. Las fuentes de energía y el } \\
\text { espacio industrial }\end{array}$ \\
\hline
\end{tabular}

TABLA 2. Hitos del recorrido y su relación con el currículo.

Fuente: Elaboración propia a partir del Ministerio de Educación, Cultura y Deportes, 2014. 


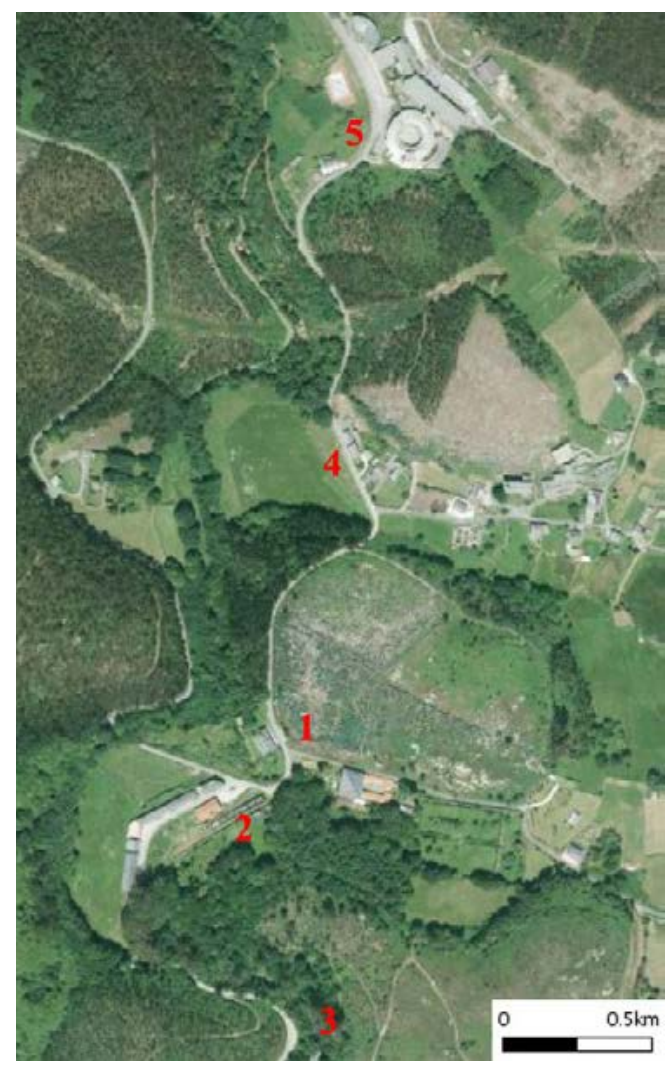

FIGURA 12. Paradas clave del walking tour.

Fuente: Elaboración propia a partir de IGN, 2020.

Los participantes desarrollan las habilidades del pensamiento geográfico e imaginación geografica a través de diferentes contenidos y cursos. Por ejemplo, en la tercera parada, observando la presa del Río Xunco, pueden pensar por qué esta presa se instaló aquí, en qué se diferencia del uso actual de energía hidráulica, o bien, reconocer e interpretar las intervenciones humanas realizadas (Figura 12). Además, esta actividad les ofrece una oportunidad para aplicar y comparar lo aprendido en el aula en un entorno real. También se pueden incluir otros contenidos geográficos complementarios para desarrollar la habilidad para considerar el lugar de forma holística: los aspectos históricos como la industrialización en Europa y España, además de la historia regional de Galicia y local de Sargadelos. Así como adquirir una mirada estética, donde se combinan los elementos naturales e industriales de la cerámica.

Además, se contribuye al desarrollo de competencias clave, como la competencia social y cívica abordando asuntos y conflictos actuales dentro de la región, en lugar 
de centrarse únicamente en el patrimonio cultural o natural. Así, se podría abordar el controvertido caso del eucalipto, una especie invasora que ha ocupado progresivamente una gran parte de la superficie forestal de Galicia. La introducción del pino y el eucalipto en los bordes de las propiedades gallegas ha constituido una tradición en el último siglo (García Fernández, 1975). La expansión forestal de estas especies ha superado la obtención maderera en un corto tiempo, originando una transformación del paisaje rural gallego que ha conducido a tomar medidas políticas para limitar y reforestar los montes con especies autóctonas. Asimismo, se puede abordar el tema del desarrollo sostenible, mencionando la riqueza del caolín y el peligro en la mina de caolín en Cervo. Hace unos años, el deslizamiento de una parte de la mina a cielo abierto produjo problemas ambientales en Cervo. Ambos temas proporcionan el debate y fomentan el desarrollo del pensamiento crítico sobre situaciones reales.

\section{CONCLUSIÓN}

En este artículo se ha mostrado cómo las regiones donde se ha producido cerámica poseen numerosos valores educativos para la educación geográfica, no solo por su ubicación, sino también por el paisaje derivado de dicha producción. Entre estas ventajas, se ha comprobado la posibilidad de incluir la educación en Geografía como una práctica de la educación en museos. Para ello se ha optado por la metodología del walking tour, puesto que como actividad de educación no formal, permite más libertad en la selección de contenidos y aumenta la habilidad de aprendizaje autónomo de los participantes que las actividades de educación formal.

En el caso de Sargadelos, pese a ser una atracción turística que atrae numeroso público y visitas escolares, no destaca especialmente por sus actividades educativas. No obstante, las características de la zona y la influencia de la industria cerámica, con sus modificaciones del pasiaje, hacen que sea un lugar especialmente indicado para desarrollar la propuesta de walking tour que cubra una serie de contenidos para la Geografía reflejados en el currículo de Educación Secundaria Obligatoria y Bachillerato.

Los posibles contenidos para este walking tour examinan cómo la industria ha intervenido en la naturaleza, cómo está evolucionado el paisaje y qué papel juegan la fábrica antigua y la fábrica actual dentro de ese paisaje. La propuesta, aunque está planteada para los estudiantes de esta etapa educativa, podría adaptarse para grupos de adultos y familias, fomentando así el papel del museo local como elemento de cohesión social y como agente potenciador de valores sociales, tales como el desarrollo sostenible.

\section{AGRADECIMIENTOS}

A Pablo Ordás por la realización de las fotografías en Sargadelos. 


\section{BIBLIOGRAFÍA}

Alfrey, J. \& Clark, C. (2005). Clay. In J. Alfrey \& C. Clark, The landscape of industry: Patterns of change in the Ironbridge Gorge. London: Routledge.

Álvarez Munárriz, L. (2011). La categoría del paisaje cultural. Revista de Antropología Iberoamericana, 6(1), 57-80.

Arnold, D. (1985). Ceramic theory and cultural process. Cambridge: University of Cambridge.

Artero Gonell,T.(2019).La Real Fábrica: Símbolo de identidad, elemento para la cohesión social y oportunidad para que el alumnado desarrolle nuevas competencias. En M. Álvarez Areces (Ed.), Resiliencia innovación y sostenibilidad en el patrimonio industrial (pp. 183-190). Gijón: CICEES.

Asensio, M. (2001). El marco teórico del aprendizaje informal. Íber, 27. 17-40.

Asensio, M. \& Pol, E. (2001). Nuevos escenarios en educación. Aprendizaje informal sobre el patrimonio, los museos y la ciudad. Buenos Aires: Aique.

Asensio, M. \& Pol, E. (2008). Conversaciones sobre el aprendizaje informal en museos y el patrimonio. In H. Fernández Betancort (Ed.), Turismo, patrimonio y educación. Los museos como laboratorios de conocimientos y emociones. (pp. 19-60). Lanzarote: Escuela Universitaria de Turismo de Lanzarote.

Bas Ordóñez, G. (2009- 2010). La arquitectura de la Real Fábrica de Sargadelos. Espacio, tiempo y forma, 22-23, 275-301.

Byeon, J. (2008). The role of museums in promoting lifelong eudcation in Korean cities. In Seoul Museum of History (Ed.), Ways to activate lifelong education of urban history museums (pp. 197-226). Seúl: Kyungin Munhwasa.

Calaf, R. \& Fontal, O. (2002). Esculturas en la Ciudad. ¿Añadir Patrimonio o Borrarlo? Ciudad y Patrimonio: Revista de Arqueología. Arte y Urbanismo, 6, 175-184.

Chapin, E. (24 de 9 de 2019). Sunday Walking Tours. Obtenido de Museum of the City of New York.

Choi, Y. (2011). 교육의형식성과형식화과정 에 관한고찰 [Explorar la formalidad y la formalización en la educación]. The Korean Journal of Philosophy of Education, 33, 181-206.

Coombs, P. H. \& Ahmed, M. (1974). Background of the Study. In Attacking Rural Poverty: How Non-formal Education Can Help (pp. 3-9). Baltimore: John Hopkins University Press.

Díaz-Maroto, I. (2019). Cerámica de Sargadelos: Arquitectura integrada en el paisaje. In M. Álvarez Areces (Ed.), Resiliencia, innovación y sostenibilidad (pp. 219-226). Gijón: CICEES. 
García de la Vega, A. (2004). El itinerario geográfico como recurso didáctico para la valoración del paisaje. Didáctica Geográfica, 6, 79-95.

García de la Vega, A. (2011). El paisaje: un desafío curricular y didáctico. Didácticas Específicas, 14, 1-19.

García de la Vega, A. (2014). Didáctica del paisaje. Realidad y reto educativo. Aula verde: revista de educación ambiental, 42, 8-9.

García de la Vega, A. (2019). Perspectivas de futuro en el aprendizaje del paisaje. Didáctica Geográfica, 20, 55-77. https://doi.org/10.21138/DG.441

García Fernández, J. (1975). Organización del espacio y economía rural en la España atlántica, Madrid: Siglo XXI.

Hammond, L. (2018). The place of fieldwork in geography education. In M. Jones y D. Lambert (Ed.), Debates in Geography Education. Oxon: Routledge.

Hein, G. E. (1998). Learning in the museum. London y Nueva York: Routledge.

Hein, G. E. (2006). Museum Education. In S. MacDonald (Ed.), A Companion to Museum Studies (pp. 340-352). Oxford: Blackwell Publishing.

Hernández Carretero, A. (2010). El valor del paisaje cultural como estrategia didáctica. Tejuelo: Didáctica de la Lengua y la Literatura. Educación, 9, 162-178.

Homobono, J. I. (1987). Modificación del paisaje, recursos naturales y culturales, y ordenación del territorio en el Valle de El Regato (Barakaldo). Lurralde, 239-283.

Hooper-Greenhill, E. (2007). Museums and education: purpose, pedagogy, performance. Abingdon y Nueva York: Routledge.

Huerta, R. (2010). Maestros y museos: Educar desde la invisibilidad. Valencia: Universidad de Valencia.

ICOM. (2014). La Carta di Siena. Museos y paisajes culturales. Siena.

ICOM. (2017). Estatutos. Modificados y adoptados por la asamblea general extraordinaria. Paris.

Jacquemart, A. (1873). Histoire de la céramique: étude descriptive des poteries de tous temps et de tous peuples. Paris: Hachette.

Jerez García, Ó. (2012). La enseñanza de la Geografía en el ámbito educativo formal, no formal e informal. Reflexiones epistemológicas. Serie Geográfica, 18, 13-23.

Jung, H. (2018). Hein 의구성주의박물관교육이론 [Teoría de la educación del museo constructivista de Hein]. The Journal of Museum Education, 19, 12-15.

Kang, K. (2012). 한국도자사[Historia de la cerámica coreana]. Seúl: Yekyong.

Khor P. S. (2005). Sustainable Mining of the Clay Resources in Peninsular Malaysia. Geological Society of Malaysia Bulletin, 51, 1-5. 
Lebrún Aspíllaga, A., M. (2015) La educación formal, no formal e informal: una tarea pendiente en los museos del Perú. Consensus, 20 (2), 25-40.

Liceras Ruiz, Á. (2018a). Notas para el estudio del paisaje. UNES, 4, 26-39.

Liceras Ruiz, Á. (2018b). Los itinerarios didácticos en la enseñanza de la Geografía. Reflexiones y propuestas acerca de su eficacia en educación. UNES, 5, 66-81.

Livingstone, D. W. (2001). Adults' informal Learning: Definitions, Findings, Gaps and Future Research (No. Working paper 21). Toronto: OISE/UT.

Livingstone, D.W. (2006) Informal Learning: Conceptual distinctions and preliminary findings. In Z. Bekerman, N. C. Burbules y D. S. Keller (Ed.) Learning in places - the informal education reader (pp. 203-228). New York: Peter Lang.

Martínez de Pisón. (2010). Valores e identidades. In E. Martínez de Pisón y N. Ortega Cantero (Eds.), El paisaje: Valores e identidades (pp. 11-45). Madrid: Ediciones de la Universidad Autónoma de Madrid.

Martul Vázquez, P. (1999). La musealización de Sargadelos. Museo: Revista de la Asociación Profesional de Museólogos de España, 4, 193-200.

Martul Vázquez, P. \& Varela Zapata, J. (2009). El proyecto ilustrado y la influencia inglesa en el desarrollo industrial de Sargadelos. Revista Antropológicas, 11, 193204.

Medley, M. (1980). The Chinese potter: a practical history of Chinese ceramics. London: Phaidon Press.

Michelaki, K., Hancock, R. \& Braun, G. (2015). Local clay sources as histories of human-landscape interactions: A ceramic taskscape perspective. Journal of Archaeological Method and Theory, 783-827. https://doi.org/10.1007/s10816$\underline{014-9204-0}$

Ministerio de Educación, Cultura y Deporte (2014). Real Decreto 1105/2014, de 26 de diciembre, por el que se establece el currículo básico de la Educación Secundaria Obligatoria y del Bachillerato. Madrid.

Ministerio de Educación, Cultura y Deporte (2015a). Plan Nacional de Paisaje Cultural. Madrid: Ministerio de Educación, Cultura y Deporte.

Ministerio de Educación, Cultura y Deporte. (2015b). 100 Paisajes Culturales en España, Madrid: Ministerio de Educación, Cultura y Deporte.

Montenegro Valenzuela, J. (2011). El museo como instrumento en la didáctica del patrimonio. Patrimonio Cultural de España, 5, 137-149.

Museo de Hanseong Baekje de Seúl. (2020). 교육홍보안내[Información y promoción de la educación]. 
Pérez Melgar, M. \& Morón Monge, H. (2016). El itinerario didáctico como herramienta para la activación patrimonial: una experiencia docente desde el parque María Luisa. Campo Abierto, 35 (2), 83-94.

Pérez Vázquez, E. (2011). Sargadelos a través da cerámica. Asociación de Ceramología (Ed.) La cerámica en Galicia: de los Castros a Sargadelos (pp. 115-122). S.L: Asociación de Ceramología.

Prado Gómez, A. (1993). Sargadelos, una experiencia ilustrada precapitalista. Boletín do Museo Provincial de Lugo, 6, 29-51.

Presidencia del Gobierno de España (1985). España. Ley 16/1985, de 25 de junio, del Patrimonio Histórico Español.

Rangiya, J. G. (2007). Ceramic industry in Gujarat. (Tesis doctoral, Gujarat University, Ahmedabad, India)

Rodrigues da Silva, R. (2012). Cultural landscape and industrial heritage: Possibilities for the Brazilian studies. XVth lnternational TlCClH Congress. Taipei, Taiwan.

Rogers, A. (2004). Ideologues. In Non-Formal Education-Flexible Schooling or Participatory Education? (pp. 92-103). Hong Kong: The University of Hong Kong Kluver Academic Publishers.

Schlereth, T. (2016). Object Knowledge: Every museum visitor and interpreter. En S. Nichols (Ed.), Patterns in practice. Selections from the Journal of Museum Education. Oxon y New York: Routledge.

Sebastiá Alcaraz, R. \& Blanes Nadal, G. (2001). Aproximación al entorno desde los museos industriales en la provincia de Alicante. In E. Tonda Monllor \& A. Mula Franco (Eds.), Scripta in memoriam. Homenaje al profesor Jesús de Vera Ferre (pp. 425-436). San Vicente del Raspeig: Publicaciones de la Universidad de Alicante.

Sebastiá Alcaraz, R. \& Blanes Nadal, G. (2010). El itinerario didáctico industrial: El problema de la puesta en práctica en los principios teóricos en el "Molinar" de Alcoy (Alicante). Didáctica Geográfica, 11, 111-140.

Sebastiá Alcaraz, R. \& Tonda Monllor, E. (2000). Aproximación al entorno industrial en la comunidad valenciana. In J. Pagés Blanch, J. Estepa Giménez \& G. Travé González (Coords.), Modelos, contenidos y experiencias en la formación del profesorado de Ciencias Sociales (pp. 215-234). Huelva: Universidad de Huelva.

Serrat Antolí, N. (2007). Acciones didácticas y de difusión en museos. In J. Santacana Mestre \& N. Serra Antolí (Coords.), Museografía Didáctica (pp. 103-206). Barcelona: Ariel.

Sodano, C. (2017). Cultural Landscapes in International Charters. Museum international, $82-85$. 
Symonds, L.A. (1999). Landscape and Social Practice: The production and consumption of pottery in tenth century Lincolnshire. Tesis doctoral. York (Inglaterra): University of York.

Tafalla, M. (2015). Paisaje y sensorialidad. In T. Luna y I. Valverde (Dirs.), Teoría y paisaje II: paisaje y emoción. El resurgir de las Geografías emocionales (pp. 115-135). Barcelona: Observatorio del Paisaje de Cataluña; Universidat Pompeu Fabra.

The International Committee for the Conservation of the Industrial Heritage. (2003). Carta De Nizhny Tagil Sobre El Patrimonio Industrial. Moscú.

Tilden, F. (1977). Principles of interpretation. In F. Tilden, Interpreting our heritage (pp. 3-10). S.L.: The University of North Carolina Press.

Trachana,A. (2011). La recuperación de los paisajes industriales como paisajes culturales. Ciudades, 14, 189-212.

UNESCO. (1994). Operational Guidelines for the Implementation of the World Heritage Convention.

Unión Europea. (2000). Convenio Europeo del Paisaje. Florencia.

Van Veldhuizen, A. (2017). Education toolkit- methods \& techniques from museum and heritage education. (C. Bown, Trad.) Utrecht: LCM, the Erfgoedhuis ZuidHolland y ICOM-CECA.

Volkova, E. (2017). Sargadelos and the Aesthetic Formation of Galician Identity. In B. Sampedro Vizcaya \& J. A. Losada Montero (Eds.), Rerouting Galician Studies. Multidisciplinary Interventions (pp. 315-330). Cham: Palgrave Macmillan.

Vrkljan, G. L \& Konestra, A. (2018). Pottery Production, Landscape and Economy of Roman Dalmatia. Interdisciplinary approaches. Oxford: Archaeopress Publishing.

Zhan, J. (2012). The Cultural Landscape of Ceramic Workshops in Jingdezhen. Scientia Geographica Sinica, 32, 55-59. [texto en chino] https://doi.org/10.13249/j.cnki. sgs.2012.01.55 